\title{
Comparison of Quality of Life Between Urban and Rural Menopause Women and its Predictors: A Population Base Study
}

\author{
Hourieh Badali Haghi' ${ }^{1}$, Sevil Hakimi2 ${ }^{*}$, Mojgan Mirghafourvand ${ }^{2}$, Sakineh Mohammad-Alizadeh \\ Charandabi $^{2}$, Mostafa Farahbakhsh ${ }^{3}$
}

\begin{abstract}
Objectives: Quality of life is a sense of physical and psychological well-being and a concept affected by various factors such as place of residence. The present study was conducted with the aim to explore quality of life of postmenopausal women in urban and rural areas of Tabriz, Iran.

Materials and Methods: The present cross-sectional study was conducted on 544 postmenopausal women from rural and urban areas, selected by cluster sampling method. Data were collected through a 3-part questionnaire consisting of demographic details, quality of life (SF-36) and a research made questionnaire for assessment of physical and psychological menopausal symptom. Results: Following adjustment of basic variables, rural women obtained significantly higher scores in "physical function", "general health" and "vitality." Although the subscales of "bodily pain," "social function and "role limitation" were better in urban women. Multivariate linear regression results revealed factors affecting quality of life, including the number of children, satisfaction with children's conduct, income, occupation and score of postmenopausal symptoms in urban women; and satisfaction with children's conduct, income, chronic diseases, age, postmenopausal duration, education, and score of postmenopausal symptoms in rural women.

Conclusion: The present study results showed that various dimensions of quality of life were at an acceptable level, but the two groups were significantly different in most subscales. Considering the increasing middle-aged and older population, attention to the quality of life of women in these age groups is crucial. The present study determined the difference in dimensions of quality of life between urban and rural women and identified their possible health requirements.

Keywords: Health, Menopause, Quality of life, Women
\end{abstract}

\section{Introduction}

The World Health Organization (WHO) defines quality of life (QOL) as one's perception of their living conditions based on the culture and value system in which they live as well as the relationship of the perception with objectives, expectations and standards (1).

In fact, the concept of QOL comprises physical and psychological well-being as well as those valuable characteristics caused by the sense of comfort in line with development and rational maintenance of physical, emotional and mental performance and help individuals preserve their capabilities in life activities (2).

Menopause women experience special physical and psychological changes caused by severe estrogen drop and face numerous problems such as vasomotor symptoms, sleep disorders, sexual dysfunction as well as psychological and cognitive problems such as depression, irritability and loss of memory and concentration (3). Furthermore, issues such as children's marriage and parents' or spouse's death or illness, which often occur during menopause (4), may affect QOL in these women (5).

Researches show that different factors such as living environment can affect menopausal symptoms and consequently QOL (6). Despite substantial improvement in health indicators of rural areas after 1993 (7), many villages still suffer the shortage of health services. Rural women experience some degrees of deprivation and social isolation and have little access to resources. These factors along with low levels of development in rural areas can affect QOL in rural women (8).

Some of studies addressed the effect of place of residence on QOL in menopausal women. For example, researchers in Poland found that QOL is different between menopausal rural and urban women (9). Moreover, Khademi et al found a more negative attitude to menopause in Iranian rural women than in urban women. They also found sociocultural factors to be playing a key role in both physical and mental aspects of menopause (10).

Different studies suggest reduced QOL in menopause women as a result of menopausal symptoms experienced 
by them $(11,12)$. Given QOL as an important health issue and a healthcare objective in menopause women in different communities as well as the effect of living environment on menopausal symptoms, the present study was conducted to compare QOL in urban and rural menopause women in northwest Iran.

\section{Materials and Methods}

This cross-sectional study was conducted on urban and rural menopause women in Tabriz. While the inclusion criteria comprised having amenorrhea for 1-5 years, no surgeries in the past 3 months, having physiological menopause and not taking psychiatric medications, unwillingness to participate in the study was the only exclusion criterion.

The maximum sample size calculated as per the study conducted by Hakimi et al $(\mathrm{m}=8.42, \mathrm{SD}=19.3)(13)$, $\alpha=0.05$ and precision of 0.1 was 158 . Considering a cluster study and design effect of 1.5 and dropout rate of $15 \%$, the minimum required sample size was calculated as 544 (272 in each of the urban and rural women groups).

Cluster sampling was used to consider 46 clusters for each of the urban and rural groups. Using the address list of 50-55 years old women in Tabriz Register Office, extracted from the last national census, 46 addresses were randomly selected and considered cluster heads.

A total of 23 villages of Tabriz were randomly selected for sampling. Two clusters were randomly selected for each village using the health houses information. In each cluster, 6 subjects completed the questionnaires. The sampling began from the cluster head and continued by moving leftwards sequentially. If the inclusion criteria were not met, participants were not home or were unwillingness to take part in the study, the next house was referred to. All the interviews were conducted by the first author and 2 trained interviewers. After controlling the inclusion criteria, all the participants were asked to sign a written consent form. All the subjects were free to leave the study at any stage.

Data collection tools included a socio-demographic questionnaire, Short-Form Health Survey (SF-36) and Questionnaire to Assessment Women's Experiences of Menopause.

The socio-demographic questionnaire comprised 13 items on personal information. The subjects completed the 36-item SF-36 that assessed physical and psychological health using a combination of scores obtained from eight subscales. The reliability and validity of this data collection tool was confirmed by Montazeri et al in Iran (14).

A researcher-made 44 -item questionnaire on physical and psychological symptoms, anxiety, emotions, attitude and menopausal compatibility was completed by the scores of menopausal symptoms. Psychometric evaluation of this data collection tool was conducted by assessing the face, content and constructs validities as well as internal consistency and retest reliability. The Cronbach's alpha and test-retest reliability calculated were respectively 0.96 and 0.78 (15). All the three questionnaires were completed by face-to-face interviews with all the participants.

After completing the questionnaires, the data were analyzed in SPSS 17. $P$ values of less than 0.05 were considered statistically significant. Descriptive statistics were used to describe socio-demographic characteristics, QOL and menopausal symptoms. General linear model (analysis of covariance - ANCOVA) was used to compare QOL after adjusting baseline variables such as age, education level, housing condition and satisfaction with the behavior of wife and children as well as presence of chronic diseases.

In order to determine the predictors of QOL in urban and rural women, independent variables with $P$ values of less than 0.2 in bivariate tests such as independent $t$ tests, one-way analysis of variance (ANOVA) and Pearson correlation coefficient were included in multivariate linear regression model with backward strategy.

\section{Results}

The present study was conducted on 544 urban and rural menopause women from March to September 2015. The mean age and number of children of these women was $51.8 \pm 3.1$ years and $3.7 \pm 1.3$ respectively. A total of $78.9 \%$ of the subjects were housewife, $66.6 \%$ were illiterate or had primary education, while $76.6 \%$ had moderate income levels. Table 1 gives the socio-demographic information of the study subjects in terms of place of residence.

After adjusting the baseline variables, the comparison of the mean scores of QOL showed significant differences between urban and rural menopause women in terms of physical functioning, bodily pain, general health, vitality, social functioning and role limitations due to emotional problems (Table 2).

According to the results of bivariate tests, $P$ values of less than 0.2 were attributed to number of children, satisfaction with the behavior of wife and children and education level in urban women and to number of children, satisfaction with the behavior of wife and children, occupation and presence of chronic diseases in rural women. These variables were therefore included in the linear regression model.

Results of multivariate linear regression showed that number of children, satisfaction with children's behavior, sufficiency of monthly income, occupation status and score of menopausal symptoms affect and predict $54 \%$ of variations in QOL in urban women. Although satisfaction with children's behavior, sufficiency of monthly income, presence of chronic diseases, age, duration of menopause, education level and score of menopausal symptoms are effective variables on QOL in rural women, they predict a mere $26 \%$ of the variations (Table 3 ).

\section{Discussion}

The present study was conducted to compare QOL in urban and rural menopause women. The results obtained indicated above average QOL in all dimensions of QOL 
Table 1. Comparison of Socio-Demographic Information of Urban and Rural Women

\begin{tabular}{|c|c|c|c|}
\hline Socio-demographic information & Urban ( $n=272)$ & Rural (n = 272) & $\boldsymbol{P}$ \\
\hline Mean age (y), Mean (SD) & $50.9(2.9)$ & $52.6(4.2)$ & $<0.001^{a}$ \\
\hline Mean duration of menopause $(\mathrm{y})$, mean (SD) & $3.2(1.6)$ & $2.9(1.4)$ & $0.071^{\mathrm{a}}$ \\
\hline Mean number of children, mean (SD) & $3.6(1.3)$ & $3.8(1.3)$ & $0.093^{\mathrm{a}}$ \\
\hline Employment status, No. (\%) (Housewife) & $200(78.7)$ & $229(84.2)$ & $0.116^{\mathrm{b}}$ \\
\hline Education level, No. (\%) & & & $<0.001^{\mathrm{b}}$ \\
\hline Illiterate & $60(22.2)$ & $111(40.8)$ & \\
\hline Primary-secondary school & $132(48.6)$ & $141(53)$ & \\
\hline High school/college diploma & 47 (17.5) & $14(5.1)$ & \\
\hline University education & $32(11.9)$ & $3(1.1)$ & \\
\hline Marital status, No. (\%) & & & $0662^{\mathrm{b}}$ \\
\hline Married & $237(87.1)$ & $241(88.6)$ & \\
\hline Single/divorced & $17(6.2)$ & $10(3.6)$ & \\
\hline Widow & $18(6.6)$ & $21(7.2)$ & \\
\hline Sufficiency of monthly income, No. (\%) & & & $<0.001^{c}$ \\
\hline Quite adequate & $60(22.1)$ & $39(14.3)$ & \\
\hline Fairly adequate & $192(70.5)$ & $230(84.5)$ & \\
\hline Inadequate & $20(7.1)$ & $3(1.1)$ & \\
\hline Housing ownership, No. (\%) & $204(75.0)$ & $232(85.3)$ & $0.004^{b}$ \\
\hline Satisfaction with the behavior of wife, No. (\%) & $193(71)$ & $217(80.5)$ & $0.012^{\mathrm{c}}$ \\
\hline Satisfaction with children's behavior, No. (\%) & $175(64.3)$ & $210(77.5)$ & $0.001^{c}$ \\
\hline Presence of chronic diseases, No. (\%) & $88(32.4)$ & $41(15.1)$ & $0.001^{\mathrm{b}}$ \\
\hline
\end{tabular}

andependent t-test; ${ }^{\mathrm{b}} \mathrm{Chi}$-square; ${ }^{\mathrm{c}} \mathrm{Chi}$-square for trend.

Table 2. Comparison of the Mean Scores of QOL in Rural and Urban Women

\begin{tabular}{|c|c|c|c|}
\hline Variable & Urban & Rural & $\mathbf{p}$ \\
\hline Physical functioning & $73.7(23.4)^{b}$ & $77.3(19.2)^{b}$ & $0.021^{a}$ \\
\hline Role limitations due to physical problems & $72.4(33.9)^{b}$ & $70.1(74.1)^{b}$ & 0.103 \\
\hline Bodily pain & $75.8(19.6)^{b}$ & $71.5(16.6)^{b}$ & $0.043^{\mathrm{a}}$ \\
\hline General health & $57.8(14.8)^{b}$ & $66.0(12.7)^{\mathrm{b}}$ & $0.041^{\mathrm{a}}$ \\
\hline Vitality & $64.7(14.1)^{b}$ & $68.7(12.1)^{b}$ & $0.042^{\mathrm{a}}$ \\
\hline Social functioning & $76.5(36.4)^{b}$ & $65.8(17.3)^{\mathrm{b}}$ & $0.008^{\mathrm{a}}$ \\
\hline Role limitations due to emotional problems & $72.7(35.5)^{b}$ & $57.5(40.6)^{b}$ & $<0.001^{\mathrm{a}}$ \\
\hline Mental health & $68.9(18.7)^{b}$ & $70.5(13.4)^{b}$ & 0.063 \\
\hline
\end{tabular}

${ }^{\mathrm{a}}$ GLM (baseline variables controlled); ${ }^{\text {b }}$ Mean (SD).

in the participants. Out of 8 dimensions assessed, general health and role limitations due to emotional problems, as vulnerable dimensions of QOL, respectively received the lowest scores in urban and rural women, which is consistent with different studies (16-18).

Unlike Żołnierczuk-Kieliszek et al who reported statistically significant differences between the total score of QOL in urban and rural women (9), the present study found differences in some dimensions of QOL in the two groups.

Rural women studied had higher mean age and satisfaction with their children and lower socioeconomic status compared to the urban population. Physical functioning, general health and vitality were found to be higher in the studied rural compared to urban women, a potential cause of which is different lifestyle and higher mobility in rural women.

The present study found lower bodily pain in urban women. Davatchi et al, who conducted a comprehensive study in Iranian villages, found higher prevalence of musculoskeletal pain in rural women compared to those in urban women. The occupation of most Iranian villagers, especially in small villages, is mainly agriculture, which is non-mechanized in some cases (19). People in rural areas therefore do more physical work than they do in urban areas. Furthermore, the present study found $7 \%$ of the women to be helping their spouse with agriculture. The difference in bodily pain is therefore justifiable given this rural lifestyle.

Social functioning was found to be higher in the studied urban women compared to rural women. Women living in towns have generally more opportunities to engage in sociocultural and economic activities (20) and naturally have better social functioning compared to rural women.

Role limitations due to emotional problems were also found to be significantly better in urban women compared to rural women, which can be justified by little access to psychiatric services in villages. Unlike other studies mental health in this study was not significantly different between rural and urban women $(9,21,22)$.

According to the regression model, income, satisfaction with children and menopausal symptoms are predictors 
Table 3. Multivariate Predictors of QOL Among Urban and Rural Menopausal Women $(n=544)$

\begin{tabular}{|c|c|c|c|c|}
\hline \multirow{2}{*}{ Variable } & \multicolumn{2}{|c|}{ Urban Women, n = 272} & \multicolumn{2}{|c|}{ Rural Women, $\mathbf{n}=\mathbf{2 7 2}$} \\
\hline & B (95\% Cl) & $\boldsymbol{P}$ & B $(95 \% \mathrm{Cl})$ & $\boldsymbol{P}$ \\
\hline Number of children & $-2.97(-4.6$ to -1.38$)$ & 0.009 & - & \\
\hline \multicolumn{5}{|l|}{ Occupation } \\
\hline Housewife & Referent & 0.035 & - & - \\
\hline Employed & $4.46(-2.72$ to -7.29$)$ & & & \\
\hline \multicolumn{5}{|l|}{ Sufficiency of monthly income } \\
\hline Fairly adequate & Referent & & Referent & \\
\hline Inadequate & $-6.9(-12.7$ to -0.1$)$ & 0.021 & $-4.46(-6.72$ to -0.29$)$ & 0.035 \\
\hline \multicolumn{5}{|l|}{ Satisfaction with children's behavior } \\
\hline Satisfied & Referent & 0.021 & Referent & 0.011 \\
\hline Dissatisfied & $-2.7(-8.2$ to -1.2$)$ & & $-3.1(-9.2$ to -0.2$)$ & \\
\hline Score of menopausal symptoms & $-0.39(-0.55$ to -0.36$)$ & $<0.001$ & $-0.433(-0.64$ to -0.22$)$ & $<0.001$ \\
\hline Duration of menopause $\mathrm{a}^{\mathrm{a}}$ & - & - & $-1.9(-3.2$ to -0.7$)$ & 0.002 \\
\hline Age $^{a}$ & - & - & $-0.4(-0.8$ to 0.03$)$ & 0.07 \\
\hline Education levela & & - & & \\
\hline School diploma & - & & Referent & 0.001 \\
\hline University education and high & & & 12.8 (7.3 to 18.5$)$ & \\
\hline Illiterate and primary school & & & $-11.4(-21.1$ to -4.5$)$ & 0.002 \\
\hline Chronic diseases $^{a}$ & & - & & \\
\hline Presence of chronic diseases & - & & Referent & \\
\hline Absence of chronic diseases & & & $-6.03(-10.91$ to -1.20$)$ & 0.095 \\
\hline Adjusted R square & 0.54 & & 0.26 & \\
\hline
\end{tabular}

aNot appeared in the final model.

of QOL in both groups. In the urban population, occupation, income, number of children, satisfaction with children and presence of menopausal symptoms were found to predict over half of variations in the score of QOL. Although education level, income, satisfaction with children's behavior, age, menopausal duration and presence of chronic diseases were effective factors on QOL in rural women, they explained less than $30 \%$ of the variance, which indicates that other factors also contribute to QOL.

Menopausal symptoms were found to predict QOL in both groups of urban and rural women. Menopause is associated with physical and psychological changes that may affect women's health (23). Menopausal effects on QOL may be caused by biological changes associated with menopausal symptoms or sociocultural factors. Effects of socioeconomic class on QOL are well demonstrated. Research suggests that income, education level and being employed improve QOL (24).

The present research found unemployment and lack of university education contributed to lower QOL in urban and rural women respectively, while low income contributed to lower QOL in both groups. All these three indicators are regarded as socioeconomic factors. Many studies suggest that low income and education lower the score of QOL obtained in SF-36 $(16,25)$.

Chronic diseases were unexpectedly found to predict QOL only in rural women although a third of the urban population suffered chronic diseases such as diabetes and hypertension. Having any type of chronic disease can affect all dimensions of QOL (26). Furthermore, children's undesirable behavior was identified as an effective variable on QOL in both groups, possibly by affecting mental health (27).

Some studies suggest destructive effects of aging on QOL, especially on physical dimension (28-30). Age was also found a predictor of QOL in the present study rural women.

\section{Study Limitations}

The present study has strengths such as being communitybased. On the other hand, subjects living in villages in the vicinity of towns may follow urban lifestyle, which may affect the results obtained.

\section{Research Highlights}

The results obtained in this research can be used by health care system managers to develop QOL improvement programs for menopause women living in towns or villages.

\section{Conclusion}

The results obtained in the present study suggest acceptable level of QOL dimensions in urban and rural women although most domains were significantly different in the 2 groups. Menopausal symptoms, socioeconomic indicators and satisfaction with children's behavior were identified as effective factors on QOL in both groups. Given the Iranian population pyramid and growing population of middle-age and older adults in the present and future, paying attention to QOL in this age group of women is crucial. The present research identified 
differences in QOL dimensions and specified possible health needs of urban and rural women.

\section{Ethical Issues}

This study was approved by the Ethics Committee of Tabriz University of Medical Sciences, Tabriz, Iran (Ethical code: 1393. 9.27-5.4.8904).

\section{Conflict of Interests}

Authors declare that they have no competing interests.

Financial Support

This study has been supported by a grant from Tabriz University of Medical Science.

\section{Acknowledgments}

The authors would like to express their gratitude to all the study participants.

\section{References}

1. Chen Y, Lin SQ, Wei Y, Gao HL, Wu ZL. Menopausespecific quality of life satisfaction in community-dwelling menopausal women in China. Gynecol Endocrinol. 2007;23(3):166-172. doi:10.1080/09513590701228034.

2. Subramaniam M, Soh P, Vaingankar JA, Picco L, Chong SA. Quality of life in obsessive-compulsive disorder: impact of the disorder and of treatment. CNS Drugs. 2013;27(5):367383. doi:10.1007/s40263-013-0056-Z.

3. Pesteei K, Allame M, Amir Khany M, Esmaeel Motlagh $\mathrm{M}$. Clinical guide and executive health program team to provide menopausal services to women $60-45$ years. Tehran: Pooneh Publication; 2008:10-17.

4. Gibbs Z, Kulkarni J. Risk Factors for Depression During Perimenopause. In: Barnes DL, editor. Women's Reproductive Mental Health Across the Lifespan. Cham: Springer International Publishing; 2014:215-233. doi:10.1007/978-3-319-05116-1_12.

5. Greenblum CA, Rowe MA, Neff DF, Greenblum JS. Midlife women: symptoms associated with menopausal transition and early postmenopause and quality of life. Menopause 2013;20(1):22-7. doi:10.1097/gme.0b013e31825a2a91.

6. Zeidi I, Hajiagha A, Zeidi B. Reliability and validity of Persian version of the health-promoting lifestyle profile. J Mazandaran Univ Med Sci. 2012;21(1):102-113.

7. Movahedi M, Hajarizadeh B, Rahimi A, Arshinchi M, Amirhosseini K, Haghdoost AA. Trends and geographical inequalities of the main health indicators for rural Iran. Health Policy Plan. 2009;24(3):229-237. doi:10.1093/ heapol/czp007.

8. Soroushmehr H, Rafiei H, Kalantari K, Shabanali-Fami $\mathrm{H}$. The survey of socioeconomic base of rural women and its related factors (case study: Hamadan city). Rural Res. 2010;1(1):143-165.

9. Żołnierczuk-Kieliszek D, Kulik TB, Jarosz MJ, et al. Quality of life in peri-and post-menopausal Polish women living in Lublin Province-differences between urban and rural dwellers. Ann Agric Environ Med. 2012;19(1):129-133.

10. Khademi S, Cooke MS. Comparing the attitudes of urban and rural Iranian women toward menopause. Maturitas 2003;46(2):113-121. doi:10.1016/S0378-5122(03)00182-8.

11. Duffy OK, Iversen L, Hannaford PC. The impact and management of symptoms experienced at midlife: a community-based study of women in northeast Scotland. BJOG. 2012;119(5):554-564. doi:10.1111/j.14710528.2012.03276.x.

12. Utian WH, Woods NF. Impact of hormone therapy on quality of life after menopause. Menopause. 2013;20(10):10981105. doi:10.1097/GME.0b013e318298debe.

13. Hakimi S. Physical and psychological experiences of women during the menopause: development, assessment of psychometric properties of an inventory and its application [Doctoral dissertation]. Tehran: Shahid Beheshti University of Medical Science; 2013.

14. Montazeri A, Goshtasebi A, Vahdaninia M, Gandek B. The Short Form Health Survey (SF-36): translation and validation study of the Iranian version. Qual Life Res. 2005;14(3):875-882.

15. Simbar MS, Hakimi S, Tehrani FR. Designing and Validation of a Questionnaire to Assess Women's Experiences of Menopause (QAWEM). J Womens Health. 2016;25(4):A31.

16. Lam CL, Gandek B, Ren XS, Chan M. Tests of scaling assumptions and construct validity of the Chinese (HK) version of the SF-36 Health Survey. J Clin Epidemiol. 1998;51(11):1139-1147.

17. Leplège A, Ecosse E, Verdier A, Perneger TV. The French SF-36 Health Survey: translation, cultural adaptation and preliminary psychometric evaluation. J Clin Epidemiol. 1998;51(11):1013-1023.

18. Wyss K, Wagner A, Whiting D, et al. Validation of the Kiswahili version of the SF-36 Health Survey in a representative sample of an urban population in Tanzania. Qual Life Res. 1999;8(1-2):111-120.

19. Davatchi F, Tehrani Banihashemi A, Gholami J, et al. The prevalence of musculoskeletal complaints in a rural area in Iran: a WHO-ILAR COPCORD study (stage 1, rural study) in Iran. Clin Rheumatol. 2009;28(11):1267-1274. doi:10.1007/s10067-009-1234-8.

20. Neri I, Demyttenaere K, Facchinetti F. Coping style and climacteric symptoms in a clinical sample of postmenopausal women. J Psychosomatic Obstet Gynaecol. 1997;18(3):229-233.

21. Malacara JM, Canto de Cetina T, Bassol S, et al. Symptoms at pre- and postmenopause in rural and urban women from three States of Mexico. Maturitas. 2002;43(1):11-19. doi:10.1016/S0378-5122(02)00077-4.

22. Sok Yee W, Pei Lin L. Anxiety and depressive symptoms among communities in the east coast of Peninsular Malaysia: A rural exploration. Malaysian J Psychiatry. 2011;20(1).

23. Waidyasekera H, Wijewardena K, Lindmark G, Naessen T. Menopausal symptoms and quality of life during the menopausal transition in Sri Lankan women. Menopause 2009;16(1):164-170. doi:10.1097/gme.0b013e31817a8abd.

24. Genazzani AR, Nicolucci A, Campagnoli C, et al. Assessment of the QoL in Italian menopausal women: comparison between HRT users and non-users. Maturitas. 2002;42(4):267-280.

25. Franks P, Gold MR, Fiscella K. Sociodemographics, self-rated health, and mortality in the US. Soc Sci Med. 2003;56(12):2505-2514.

26. Baraz Sh, Mohammadi E, Broumand B. The effect of selfcare educational program on decreasing the problems and improving the quality of life of dialysis patients. Hayat. 2005;11(2):51-62. 
27. Amiri Majd M, Hosseini SF, Jafari A. Comparing the quality of life and marital intimacy among parents of children with Down syndrome, parents of children with learning disabilities, and parents of normal children (Persian). J Learn Disabil. 2014;4(1):38-55.

28. Barati M, Ahmadpanah M, Shirahmadi S, et al. Differential Impact of Sociodemographic Variables on the Quality of Life of Menopausal Iranian Women. Avicenna J Neuropsychphysioly. 2016;3(2):e39026. doi:10.17795/ ajnpp-39026.

29. Lucumi DI, Gomez LF, Brownson RC, Parra DC. Social capital, socioeconomic status, and health-related quality of life among older adults in Bogota (Colombia). J Aging Health. 2015;27(4):730-750. doi:10.1177/0898264314556616.

30. Alexandre TdaS, Cordeiro RC, Ramos LR. Factors associated to quality of life in active elderly. Revista de Saúde Pública 2009;43(4):613-621. doi:10.1590/S003489102009005000030 .

Copyright (c) 2017 The Author (s); This is an open-access article distributed under the terms of the Creative Commons Attribution License (http://creativecommons.org/licenses/by/4.0), which permits unrestricted use, distribution, and reproduction in any medium, provided the original work is properly cited. 